CHAPTER 11

\title{
SCALE EFFECTS INVOLVING THE BREAKING OF WAVES
}

\author{
J.G.H.R. Diephuis \\ Hydraulics Laboratory Delft, Holland.
}

\section{INTRODUCTION}

When in the period after 1953 the projects to damm up the estuaries in the south western part of the Netherlands took shape and it turned out to be necessary to let very wide discharge sluices into at least one of them, the problem arose which waves had to be taken into account at the structure before, during and after the construction. The waves occurring at high tides and storm surges are determinant for the definite shape and dimensions of the sluices. Wore frequently occurring waves have to be reckoned with during the construction. Though, especially in recent years, many measurements have been done in nature by the Rijkswaterstaat, supplementary calculations and nodel investigations avpeared necessary, to determine the design criteria at rarely occurring circumstances.

The shoals before and in the estuaries have a very capricious shape. This fact and the often very strong tidal currents practically prevent accurate calculations of refraction and diffraction. Moreover, there has to be reckoned with the influence of the local wind and with the breaking of the waves on the offshore bars.

All this considered it was decided to bult "sruall-scale model representing the estuary and the offshore area.

For the interpretation of the results of such a model, which by the large extent of the prototype should have very small scales, it was necessary to analyse certain factors, viz. the cxact influence of the internal and external friction on waves and the relation of the friction to the scale of the model, the transfer of energy from wind to waves and the relationship between the scale of the model and the loss of energy of waves at breaking.

Although the investigations of these problems are not yet all completed, the preliminary results of the latter scale effect may herewith be cormunicated.

\section{DESGRIPTION OF THE MODEL}

The loss of energy of waves passing submerged barriers has been a subject of investigations in several countries for a long time. We may cite among others the publications of Jonnson on 


\section{SCALE EFFECTS INVOLVING THE BREAKING OF WAVES}

scale effects in wave models, ref, 1, and of Johnson, Fuchs and Morison on the damping action of submerged breakwaters, ref. 2 .

Apparently in these and other studies the width of the crest of the submerged obstruction has been taken swall, compared with the length of the waves, or the influence of the absolute wave dimensions on the results have not been taken into account.

Al though rarely stated, the periods of the model waves seem to have been mostly rather long, viz. about 1 or 2 seconds.

Among the results it 1 s mentioned that the loss of energy of steep waves, passing a certain obstruction, exceeds that of flat waves and that the transmission of the energy decreases with increasing height of the obstruction. These phenomena were also observed in Delft, where it was above all a ratter of study of very small wave periods and of great width of the obstructing bar in the direction of the wave motion.

For this purpose tests have been carried out in a glass walled flume, wide $0.5 \mathrm{~m}$, with models as shown in figure 14. The models consisted of a gentle slope of $1: 10$, at the end of which was a horizontal crest, representing a bar, followed by a channel. The dimensions of the model are expressed in the deep-water wave length $L_{0}$, so that at all different wave periods-hence lergths - a suited

model was used. The top of the bar was placed at a half wave length above the level of the botton of the flume, so that the incident wave always was a deep-water wave. The width of the bar in the dit. rection of the wave motion was three wave lengths. The models were made of glass to reduce the wall and bottom friction to a minimum and to permit an accurate finishing.

The water level ranced from $0.05 \mathrm{~L}_{0}$ to $0.3 \mathrm{~L}_{0}$ above the level of the bar and the wave steepness from 0.02 to ${ }^{\circ} 0.08$. The investigated wave periods were $0.31,0.43$ and 0.55 seconds; the corresponding wave lengths were $0.15 \mathrm{~m}, 0.29 \mathrm{~m}$ and $0.47 \mathrm{~m}$ respectively.

In order to determine the correct scale laws for very small wave models, it is necessary to continue these tests with greater wave periods.

\section{THE TESTS}

During the tests the surface of the water was repeatedly cleaned because of the experience, that even a thin and unvisible cover of dust increases the surface tension and diminishes considerably the height of waves of small periods. Separate tests have been carried out in the sane flume to determine the loss of energy due to viscosity and side-wall friction. The results of these tests 


\section{COASTAL ENGINEERING}

Fig 1

Ho

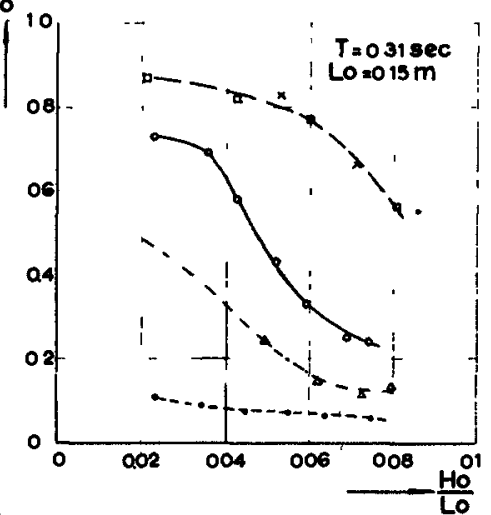

$\frac{H}{H o}$

Fig 3

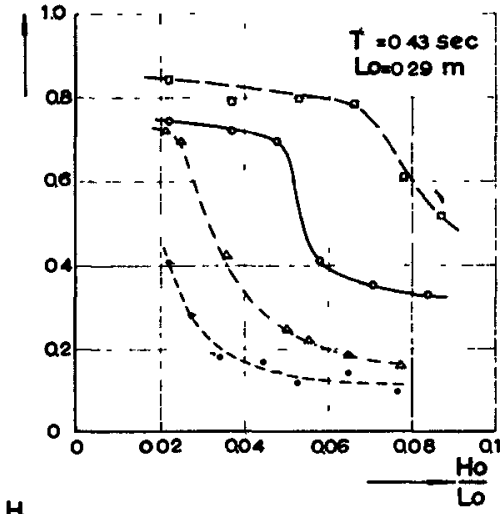

Fig 5

HO

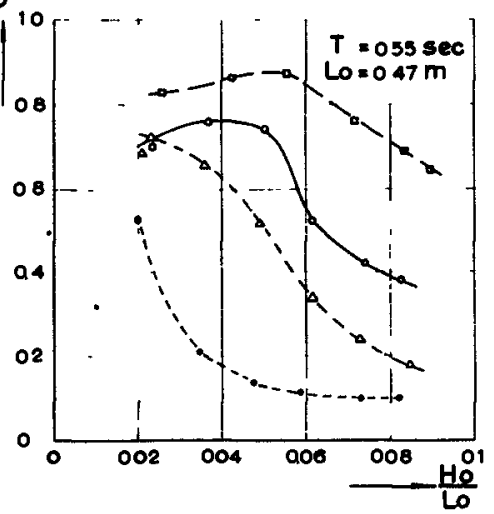

Lo

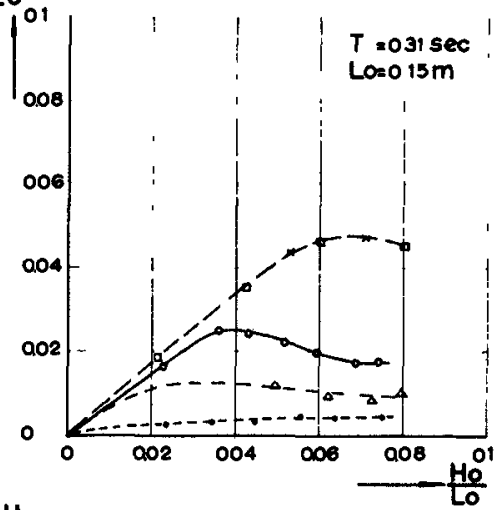

$\frac{H}{L 0}$

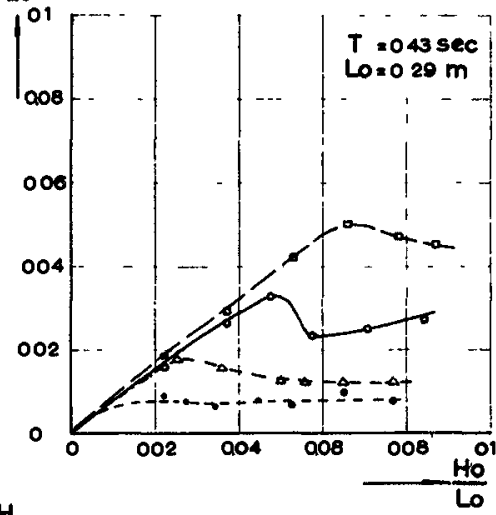

논o

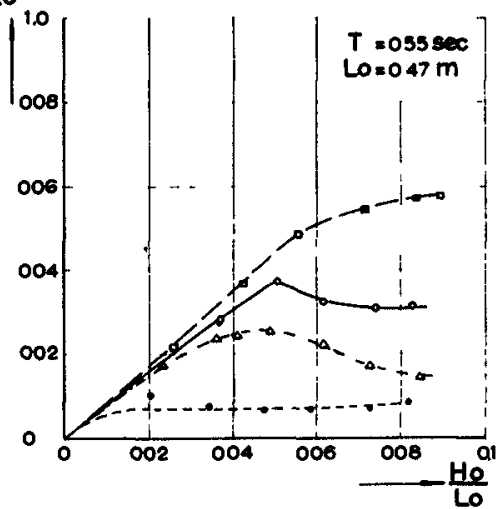

Fig :

Fig 4

Fige

Fig 1,3,5-Reiotionship between the rotio of the wove height behind the bar to the incident wove height ond the wave steepness in deep woter

Fig 2,4,6-Reiotionship between the steepness of the woves before ond behind the bar 


\section{SCALE EFFECTS INVOLVING THE BREAKING OF WAVES}

have been taken into account in the interpretation of the tests concerning the breaking of the waves.

The experimental data are shown in a number of diagrams. The figures 1,3 and 5 show for different wave perıods - z.e. different wave lengths $\mathrm{H}^{-}$the relationship between the steepness of the incident wave $\left(\frac{0}{\mathrm{~L}_{0}}\right)$ and the ratio of the wave height before the bar to the wave height behind the bar $\left(\frac{1}{H_{0}}\right)$ the transmissiun coefficient. The figures 2,4 and 6 show the relationship between the steepness of the waves before and behind the breaking zone, $\frac{\mathrm{H}_{0}}{\mathrm{~L}_{0}}$ and $\frac{\mathrm{H}}{\mathrm{L}_{\mathrm{o}}}$ respectively.

The tests have been performed at four different water levels. The figures $7,8,9$ and 10 show the results for each water level separately. It appears that the water depth above the bar is of outstanding significance. For each water depth there exists a definite wave steepness for which the transmission coefficient is naximus. Of more importance is, however, that this re! ation varues with the wave period. With deceasing periods the transinision decreases. The ratios $\frac{D}{L_{0}}$ and $\frac{H_{0}}{L_{0}}$ beirg constant, the transmitted wave energy with a wave period of 0.55 seconds may be the threeto fourfold of that with a wave period of 0.31 seconds. With 1 arger waves, having periods of 2 to 3 seconds, the quantity of transmitted energy will be ever greater.

For a small-scale model this means a linutation of the possibilities. The given boundary conditions may not always be met and often smaller wave heights will have to be used, to avold breaking. For refraction models this is rather inconvenient. The influence of this effect can hardly be corrected, especially when the waves break more than once. The cause of the stated differences can be found in the properties of the liquid, notably the surface tension and the viscosity.

From the relationship between the wave height and the covered stretch in the nodel, see figure 14, it appears that the decrease of the wave height does not remain constant for waves having the same steepness but different periods, see figures 15 and 16 . The relative depths, where a marked decrease of the wave height begins, - which for very small waves is not identical wath the depth, where a vasible breaking occurs - increases with decreasing wave period. In the case of the smallest waves the conversion of the energy occurs by viscous friction after the origination of a capillary wave train. It is the intention to repeat a part of the tests with 
Fig 7

Ho

Fig 9

$\frac{H}{L 0}$

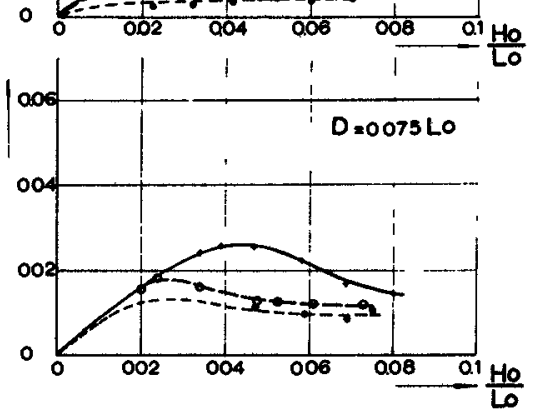

$\frac{H}{10}$

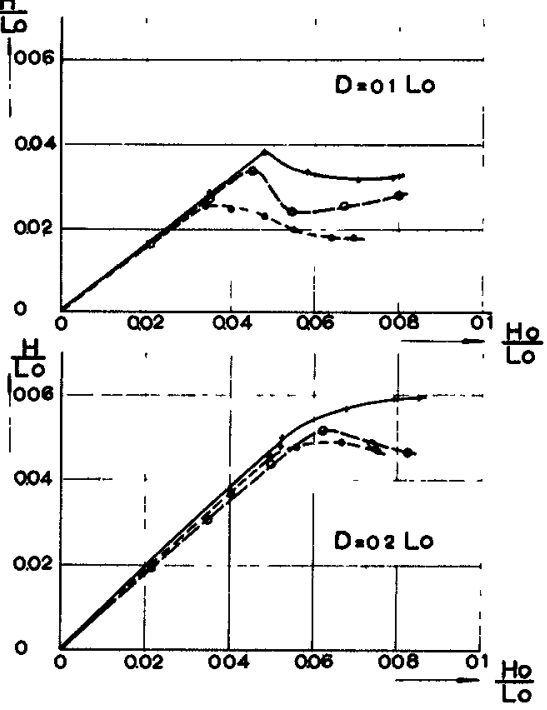

Fig 1

Fig 7,8,9,10-Relationship between the steepness of the waves before and behind the bar

Fig 11
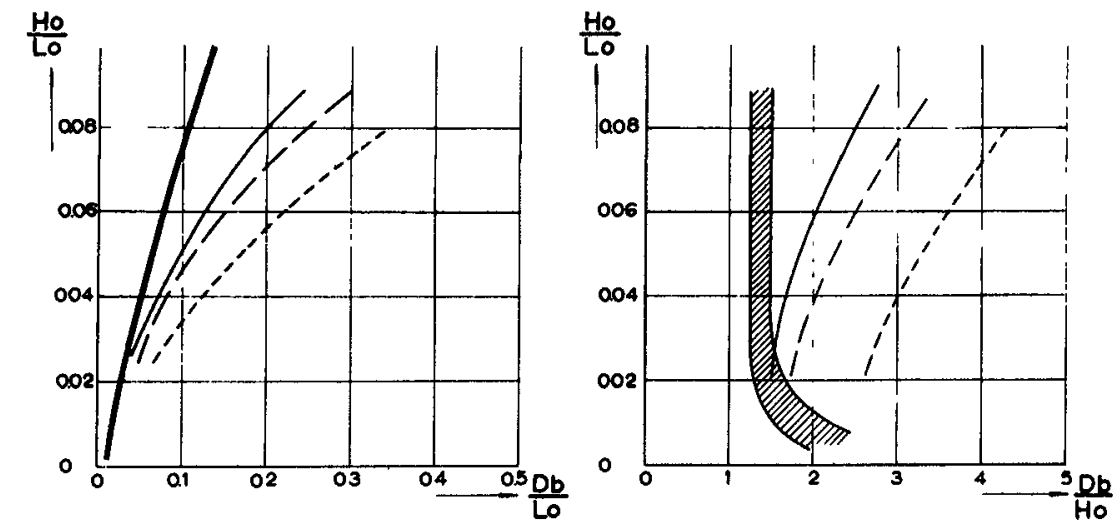

Fig *

Fig 11 -Relationship between the steepness of the in cident wove and the rotio of the depth ot breaking to the deep-woter wove length

Fig 12 -Relotionship between the steepness of the incident wove ond the rotio of the depth at breok-ing to the deep-woter wove height

TXYT Experimentol data of foreign investigotors Wove periods 1-3 si

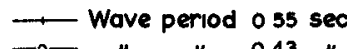

-0. " " 0.43 "

$-\infty$ " 1031 " 


\section{SCALE EFFECTS INVOLVING THE BREAKING OF WAVES}
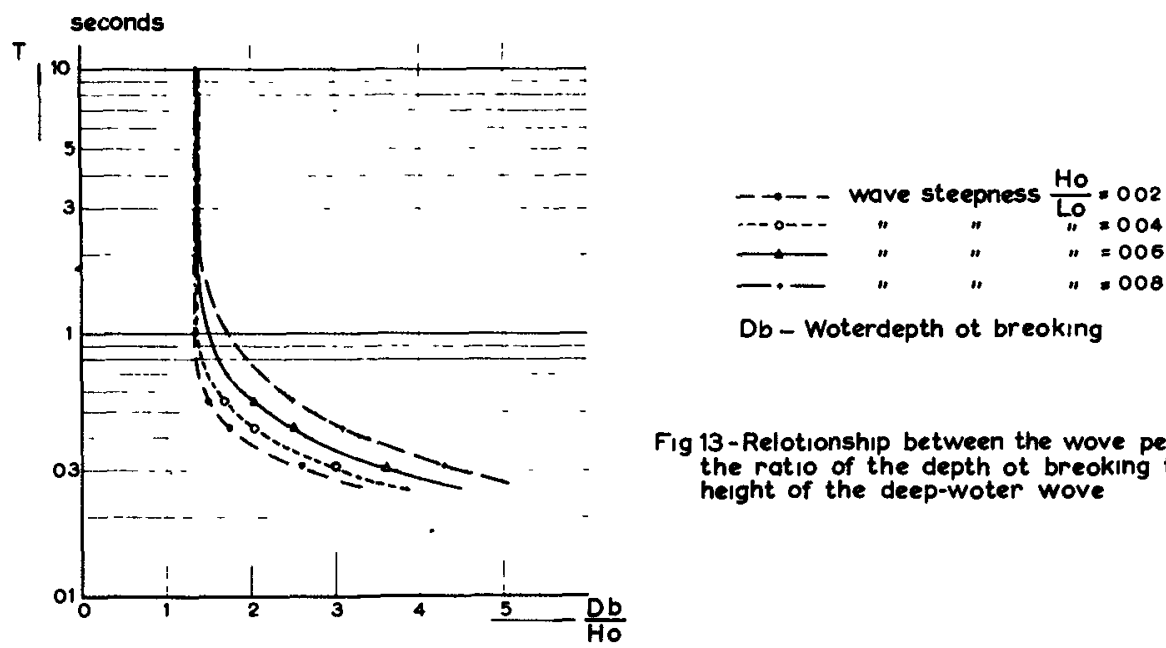

Db - Woterdepth ot breoking

Fig 13-Relotionship between the wove period and the ratio of the depth ot breoking to the height of the deep-woter wove

Fig 14 - Cross-section of the models

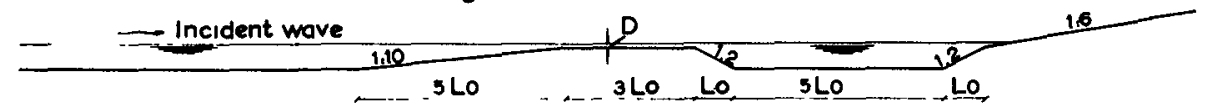

Fig 13

Fig 16

Fig 17

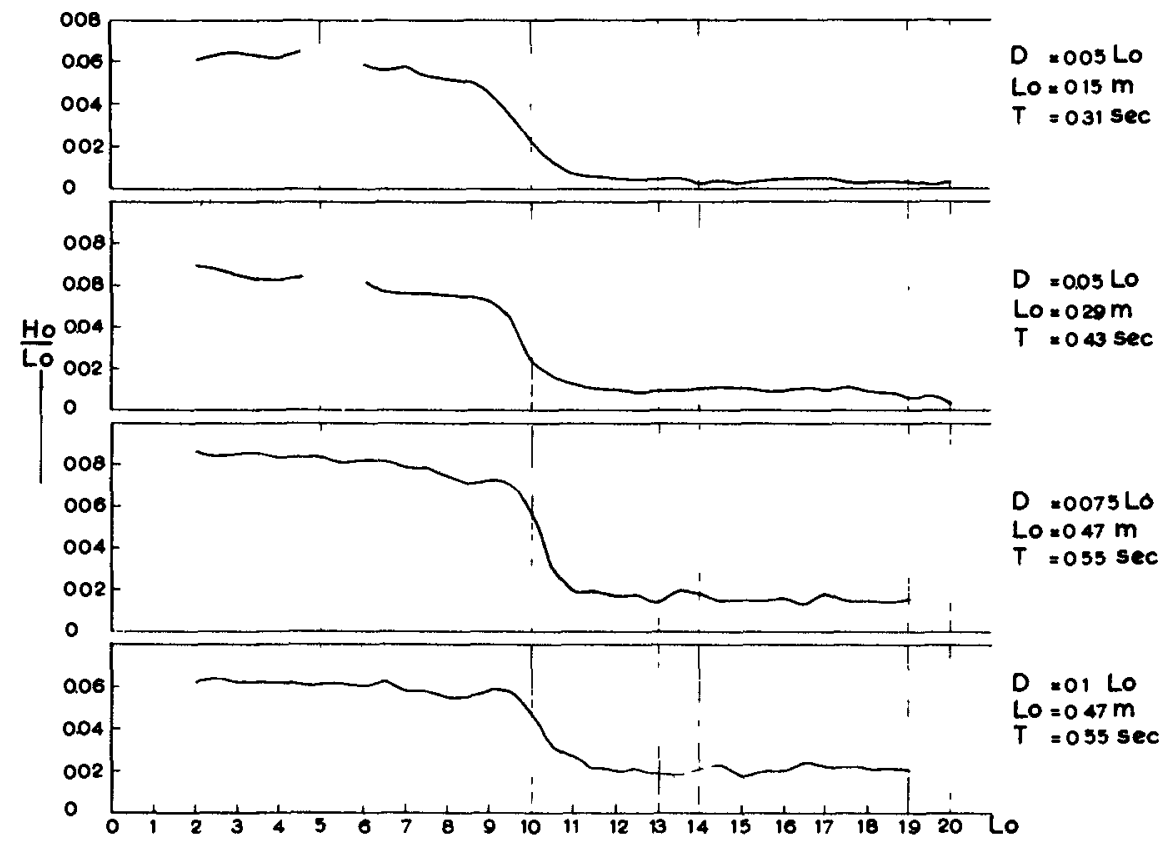

Fig 15,16,17,18-Typical wove height diograms 


\section{COASTAL ENGINEERING}

a liquid having another - smaller - surface tension.

On the figures 11 and 12 the relationship is shown between the steepness of the incident wave $\frac{\mathrm{H}_{0}}{\mathrm{~L}_{\mathrm{O}}}$ and the ratio of the depth of breaking to the length and to the height of the incident wave, $\frac{D_{b}}{L_{0}}$ and $\frac{D_{b}}{H_{0}}$ respectively. On these are also indicated the experi mental data of other investigations, viz. Larras, ref. 3, Iversen, ref. 4, Hensen, ref. 5, and the University of California, ref. 1 , No tests have been performed in Delft with very small steepness. The deviations are considerable in the case of very small periods. Larras mentions this phenomenon but gives no further data.

The relationship between the ratio of the depth of breaking to the wave length $\frac{D_{b}}{L_{0}}$ and the wave period is shown on flgure 13

The period is of no influence if it is longer than about 2 seconds Most investigators used waves with periods longer than 1 second and by that reason they could observe little or nothing of the influence of the surface tension.

\section{CONCLUSIONS}

With the breaking of waves on a submeryed bar there exists 8 considerable scale effect in the transmission of the energy - henc the helght - of the waves. With small weve periods more energy is converted into heat than with long periods. This applies notably 1 obstructions having a width of the crest in the direction of the wave motion of more than one deep-water wave length. This is cause by the surface tension. It is impossible to obtain absolute quantitatıve data from small models, e.g. of large estuaries, because the effects of scale impose too many limitations.

In calculations of refraction is, behind the point of breaking, always reckoned with the maxımum height of a wave that coul pass without breaking. This supposition appears to be safe.

The influence of the wave height and the viscosity on the velocity of propagation can be neglected in practice. Hence, a model of an estuary, when it is inacessable for calculations, can provide very usefull indications for the diagrams of refraction, especially when the tidal currents interfere.

The ratio of the depth of breaking to the deep-water wave 


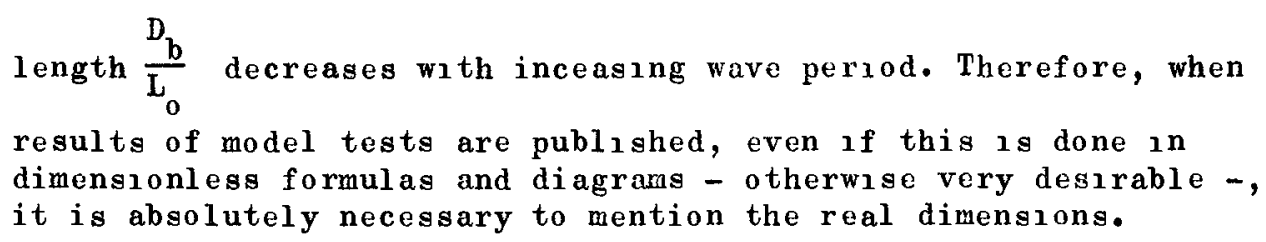

\section{REFERENCES}

1. JOHNSON, J.W., Scale effects in hydraulic models involving wave motion. Trans. Amer. Geophys. Union, v. 30, pp. 517 525,1949 .

2. JOHNSON, J.W., FUCHS, R.A., and MORISON, J.R., The damping action of submerged breakwaters. Trans. Amer. Geophys.Union, v. 32, pp. $704-718,1951$ d.

3. LARRAS, J., Recherches expérimentales sur le déferlement des 1 ames. Annales des Ponts et Chaussés no. 5, Sept.0ct.1952.

4. IVERSEN, H.W., Laboratory Study of Breakers, Gravıty Waves. National Bureau of Standards Circular 521, 1ssued 1952.

5. HENSEN, W., Modellversuche über den Wellenauflauf an Seedeichen im Wattengebiet. Mittellungen der Uannoverschen Versuchsanstalt für Grundbau und Wasserbau, Franzius-Institut der Technischen Hochschule Hannover, Heft 5, 1954. 